\title{
JENIS-JENIS Hoya (APOCYNACEAE) DI GUNUNG SIDOLE, KECAMATAN AMPIBABO, KABUPATEN PARIGI MOUTONG, SULAWESI TENGAH
}

\section{Diversity of Hoya (Apocynaceae) at Mount Sidole, Ampibabo District, Parigi Moutong Regency, Central Sulawesi}

\author{
Roland P. P. Ahmad dan Ramadanil \\ Jurusan Biologi Fakultas Matematika dan Ilmu Pengetahuan Alam Universitas Tadulako Tondo Palu, \\ Sulawesi Tengah 94118
}

\begin{abstract}
Keywords: Species diversity, Hoya, Sidole Mountain, Central Sulawesi

A research about species diversity of Hoya (Apocynaceae) in Sidole Mountain, Ampibabo District, Parigi Moutong Regency of Central Sulawesi has been conducted from December 2018 to March 2019. The research was conducted by using botanical exploration method that aim to record and describe species of Hoya based on morphological characters The results showed that there were 2 species of Hoya namely $H$. camphorifolia Warb and $H$. imbricata Decne.

Kata Kunci:

Eksplorasi,

Hoya,

Gunung

Sidole,

Sulawesi

Tengah

\section{ABSTRAK}

Telah dilakukannya penelitian tentang jenis-jenis Hoya (Apocynaceae) di gunung Sidole, kecamatan Ampibabo, kabupaten Parigi Moutong, Sulawesi Tengah dari bulan bulan Desember 2018 sampai dengan Maret 2019. Penelitian menggunakan metoda eksplorasi botani yang bertujuan untuk mendata dan mendeskripsikan jenis-jenis Hoya berdasarkan kajian morfologi. Hasil penelitian ini menunjukan bahwa terdapat 2 jenis Hoya yaitu $H$. camphorifolia Warb dan H. imbricata Decne.
\end{abstract}

Corresponding Author : rolandputra3@gmail.com

\section{PENDAHULUAN}

Hoya (Apocynaceae) merupakan salah satu genus tumbuhan berbunga yang bersifat epifit dan dapat tumbuh dari dataran rendah hingga dataran tinggi yang memiliki kelembaban tinggi serta mendapat sinar matahari yang cukup (Rintz, 1978; Rahayu, 1997). Hoya termasuk salah satu genus terbesar di Apocynaceae yang memiliki lebih dari 300 spesies (Rodda, 2015), dengan wilayah penyebaran daerah tropis, subtropis Asia Selatan, Asia Tenggara dan Papuasia (Simonsson and Rodda, 2017). Indonesia merupakan salah satu wilayah dengan penyebaran Hoya yang terluas, dimana terdapat sekitar 32 jenis Hoya yang telah dikoleksi dan dikonservasikan di Kebun Raya Bogor (Rahayu, 1997). Beberapa wilayah di Indonesia telah dilaporkan keragaman Hoya seperti, 
Sumatera 25 jenis (Rahayu, 2001), Jawa 21 jenis (Backer and van den Brink Jr, 1965), Borneo 72 Taxa (1 sub spesies) (Lamb and Rodda., 2016) dan Sulawesi tercatat lebih dari 15 jenis yang belum terselesaikan (Kleijn and van Donkelaar, 2001). Sebelumnya Kloppenburg (1993), mengemukakan bahwa seorang botanis german Dr. Friedrich Richard Rudolph Schlecther pernah melakukan pengoleksian Hoya di wilayah Sulawesi pada tahun 1900an.

Sulawesi Tengah merupakan salah satu wilayah yang memilki tingkat keragaman jenis dan tingkat endemisitas tumbuhan yang sangat tinggi (Whitten et al. 1987), namun masih banyak informasi mengenai kelompok tumbuhan berbunga yang belum

\section{BAHAN DAN METODE}

Alat-alat yang digunakan dalam penelitian yaitu teropong digunakan untuk mengamati Hoya yang berada pada pepohonan yang sulit diamati dengan mata telanjang. Kamera digital digunakan untuk mengambil gambar sampel yang akan dikoleksi saat di lapangan. Global Positioning System (GPS) digunakan untuk mengambil titik koordinat saat melakukan pengoleksian dilapangan. Oven listrik (elektric stove) digunakan untuk pengeringan sampel. Gunting stek digunakan untuk melakukan pengoleksian. Buku lapangan dan alat tulis digunakan untuk mencatat karakter yang akan berubah terselesaikan di Sulawesi Tengah, salah satunya Hoya. Berdasarkan rekam jejak perjalanan Schlechter, Kleijn dan van Donkelaar di Sulawesi Tengah, mereka tidak melakukan pengoleksian di wilayah Gunung Sidole, Kecamatan Ambipabo, Kabupaten Parigi Moutong. Sementara Gunung Sidole memiliki karakter habitat yang menunjang keberadaannya Hoya. Salah satu langkah untuk menyelesaikan informasi mengenai jenis-jenis Hoya di Sulawesi Tengah perlu di lakukan eksplorasi di wilayah yang belum pernah dilakukan pengoleksian.

Penelitian ini diharapkan dapat menambah informasi mengenai jenis-jenis Hoya di Sulawesi Tengah.

saat dilakukan pembuatan herbarium. Kotak sampel digunakan untuk penyimpanan koleksi saat melakukan pengoleksian di lapangan. Alat pengepres (sasak dan webbing) untuk menjaga spesimen agar tidak rusak. Botol sampel digunakan untuk menyimpan bunga. Silet dan jarum pentul digunakan untuk mengambil pollinarium yang akan diamati. Kaca objek sebagai wadah pengamatan pollinarium dan mikroskop cahaya untuk mengamati pollinarium.

Bahan yang digunakan dalam penelitian ini yaitu koran untuk pengeringan spesimen. Label gantung digunakan untuk menandai sampel yang telah dikoleksi. Alkohol 96\% 
dan Gliserin 40\% untuk mengawetkan organ penting seperti bunga.

\section{Prosedur Penelitian}

Pengoleksian menggunakan metode jelajah (Rugayah et al., 2004). menjelajahi sepanjang jalur pendakian Gunung Sidole. Setelah ditemukan populasi atau individu Hoya, maka dilakukan pengambilan sampel terutama yang memiliki batang, daun, bunga dan buah, menggunakan gunting stek sebanyak 3-5 duplikat, setelah itu dilanjutkan dengan pencatatan karakter yang dapat berubah, seperti warna, ketika dilakukan pembuatan herbarium yaitu warna, panjang dan lebar bentuk sampel, baik batang, daun, bunga dan buah. Tiap contoh sampel diberikan label yang berisi informasi nomor koleksi dan tanggal pengkoleksian.

Sampel yang telah diberikan label dimasukkan ke dalam koran untuk proses pengepresan menggunakan sasak dan webbing agar sampel tidak rusak, untuk pengoleksian basah sampel generatif seperti bunga dan buah menggunakan gliserin $40 \%$ dengan perbandingan alkohol $96 \%$ : aquadest : gliserin $=70: 29: 1$.

Sampel yang didapatkan dari lapangan akan dibawa ke Laboratorium Biodiversity Jurusan Biologi Fakultas Matematika dan IImu Pengetahuan Alam Universitas Tadulako untuk proses pengeringan yang menggunakan oven listrik (elektrik stove). Sampel yang telah kering diletakkan di atas kertas bebas asam, dengan merekatkan label herbarium di sudut kanan bawah sampel yang mencantumkan karakter sampel pada paragraf pertama dan paragraf ke dua mengenai habitat dan asal sampel (Simpson, 2006).

Determinasi dan identifikasi dilakukan dengan pengamatan karakter makro morfologi dan mikro morfologi (pollinarium). Pengambilan pollinarium menggunakan silet sebagai alat penyatan bunga dan menggunakan jarum pentul untuk memindahkan pollinarium ke kaca objek. Setelah proses pemindahan pollinarium ke kaca objek, dilakukan pengamatan karakter menggunakan mikroskop cahaya yang telah tersedia di UPT. Sumber Daya Hayati (Herbarium CEB). Identifikasi jenis Hoya dibantu dengan menggunakan Catalogue Hoya yang bersumber dari "data.rbge.org.uk/search/herbarium", "apps.kew.org/herbcat" dan menggunakan buku identifikasi seperti A Guide To Hoyas of Borneo (Lamb and Rodda, 2016) dan beberapa artikel ilmiah mengenai Hoya (Schlechter, 1914; Kloppenburg, 1993; Kleijn and van Donkelaar, 2001).

\section{HASIL}

Dari penelitian yang telah dilakukan, terdapat 6 individu Hoya yang terdiri atas 2 jenis, yaitu Hoya camphorifolia Warb.dan Hoya imbricata Decne. Jenis-jenis, posisi geografi (Gambar 1.), dan habitat kedua 
jenis Hoya disajikan pada Tabel 1, morfologi kedua jenis Hoya tersebut sedangkan data perbandingan karakter disajikan pada Tabel 2.

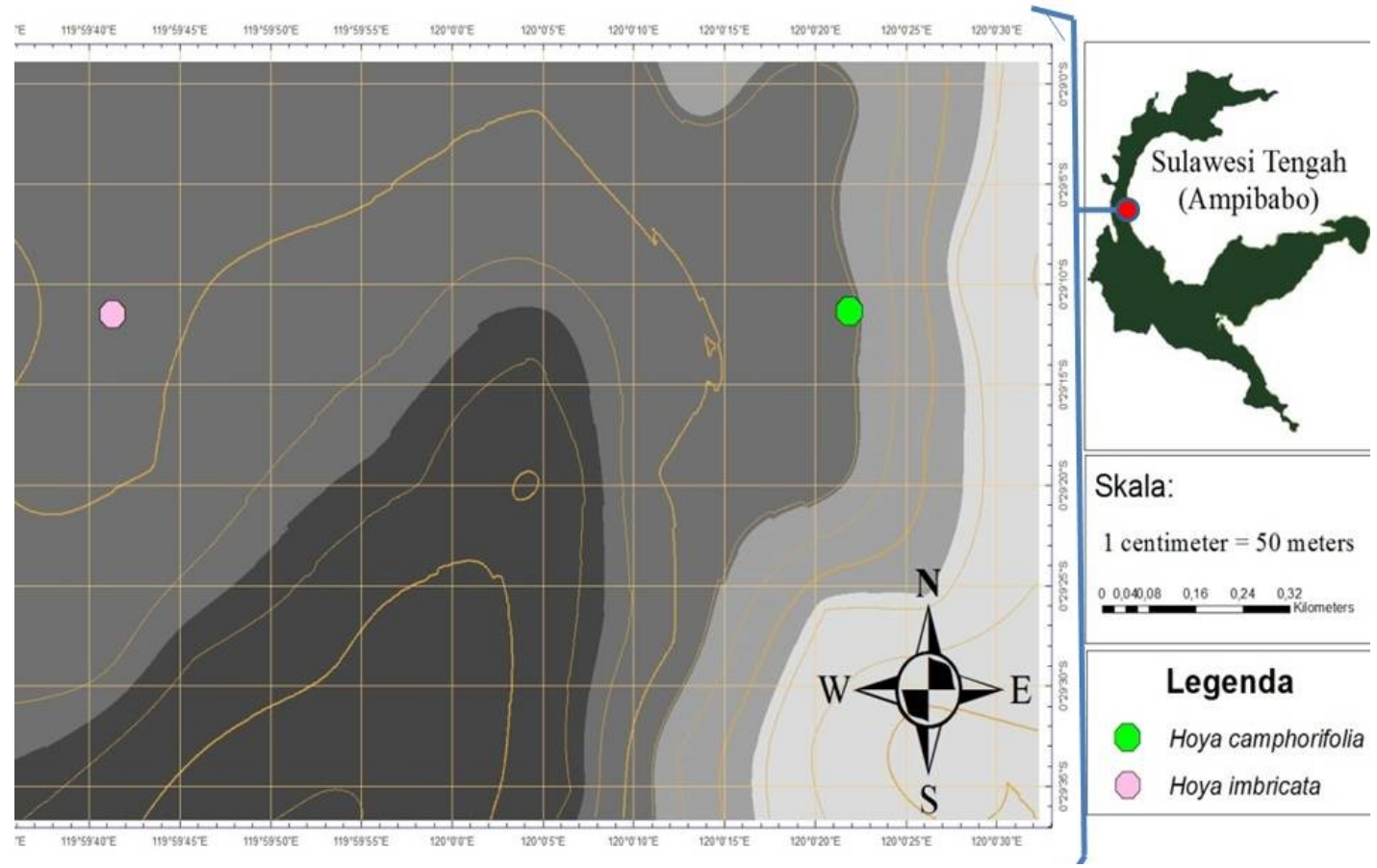

Gambar 1. Lokasi Penelitian

Tabel 1 Perbandingan karakter morfologi

\begin{tabular}{lll}
\hline \multirow{2}{*}{ Karakter } & \multicolumn{2}{c}{ Jenis } \\
\cline { 2 - 3 } Bangun daun & Hoya camphorifolia Warb. & Hoya imbricata Decne \\
Mahkota & Oval & Imbricate \\
& 5 , tidak memiliki rambut & 5 , memiliki rambut halus \\
Mahkota tambahan & Bagian dalam mahkota tambahan & $\begin{array}{l}\text { Bagian dalam mahkota tambahan } \\
\text { meruncing dan terdapat rambut }\end{array}$ \\
Pollinarium & Peruncing dan tidak terdapat rambut. & tambahan \\
Retinaculum & Membulat telur & Panjang $0,25 \mathrm{~mm}$ \\
Sayap ekor polinia & Tidak menutupi ekor polinia & Lanset \\
Anther & Memiliki anther yang bersinggungan & Menutupi ekor polinia \\
& dengan retinaculum & Memiliki anther yang tidak \\
& & bersinggungan dengan retinaculum \\
\hline
\end{tabular}




\section{Deskripsi Hoya spp}

Hoya camphorifolia Warb.

Deskripsi: Tumbuhan epifit. Batang tebal, jarak ruas $9.5-10 \mathrm{~cm}$, panjang tangkai daun 1.5-2.3 cm. Daun tepi daun ratabergelombang, ujung daun runcingmeruncing, dasar daun tumpul, tebal tanpa rambut, dengan urat tulang daun yang seperti garpu memiliki bercak merah muda sampai ungu, warna pada daun mudah berubah sesuai dengan bertambahnya usia, 6.5-13.5 × 3-4.5 cm. Perbungaan tipe bunga majemuk menyerupai payung, mengarah ke bawah, jumlah bunga 40-45, panjang ibu tangkai bunga $3.5-4 \mathrm{~cm}$

\section{Hoya imbricata Dence.}

Deskripsi: Tumbuhan epifit. Batang tebal berwarna hijau cerah hingga gelap, setiap ruas memiliki akar liar, jarak internodus 10$12 \mathrm{~cm}$. panjang tangkai daun $0.5-0.7 \mathrm{~cm}$.

Daun,tepi daun berombak, ujung daun membulat, dasar daun terbelah, bangun daun berlekuk menutupi batang dan akar tebal dan lebar tanpa bulu, warna permukaan atas hijau dengan corak ungu gelap dan bagian dasar berwarna ungu gelap, 10-11 × 10-11 cm. Perbungaan mengarah kebawah, jumlah bunga 15-30, tipe bunga majemuk menyerupai payung, ibu tangkai bunga 4-9 cm, panjang tangkai bunga 2-4.5 cm. Bunga; Kelopak 5; Mahkota 5, berwarna kuning dengan rambut berwarna putih, berwarna merah muda dengan warna ungu-hijau, panjang tangkai 1.5-1.7 cm dengan warna ungu, Bunga kelopak 5; mahkota 5, berwarna ungu, panjang $0.8 \mathrm{~cm}$, diameter $1.7 \mathrm{~cm}$; bagian mahkota tambahan berwarna merah, panjang $0.4 \mathrm{~cm}$, ujung mahkota tambahan melancip. Panjang pollinium hingga 0.25 $\mathrm{mm}$, anther yang tida bersinggungan dengan retinaculum, retinacullum membundar telur.

Habitat dan ekologi: spesimen ini dikoleksi pada jalur pendakian (tipe habitat hutan perkebunaan) pada ketinggian ca. $219 \mathrm{~m}$ dpl (LS 00²9'11,25",BT 12000'21.9").

sampai ungu dengan pada ujung dalam bagian mahkota tambahan memiliki rambut tambahan. Polinarium memiliki panjang hingga $0.5 \mathrm{~mm}$, Retinacullum berbentuk seperti segetiga dengan setiap tepi berlekuk, sayap polen menutupi tangkai polen.

Habitat dan ekologi: spesimen ini dikoleksi pada jalur pendakian (tipe habitat hutan perkebunaan) pada ketinggian ca. $223 \mathrm{~m}$ dpl (LS 00²9'11.8",BT 11959'41.33

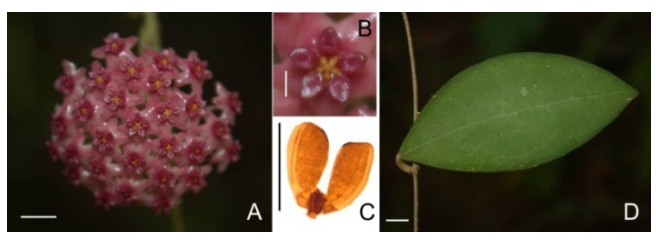

Gambar 2. A. Perbungaan, skala: $1 \mathrm{~cm}$; B. mahkota tambahan, skala: $0.4 \mathrm{~mm}$; C. Pollinarium, skala: $0.25 \mathrm{~mm}$; D. Daun, skala: $2 \mathrm{~cm}$. 


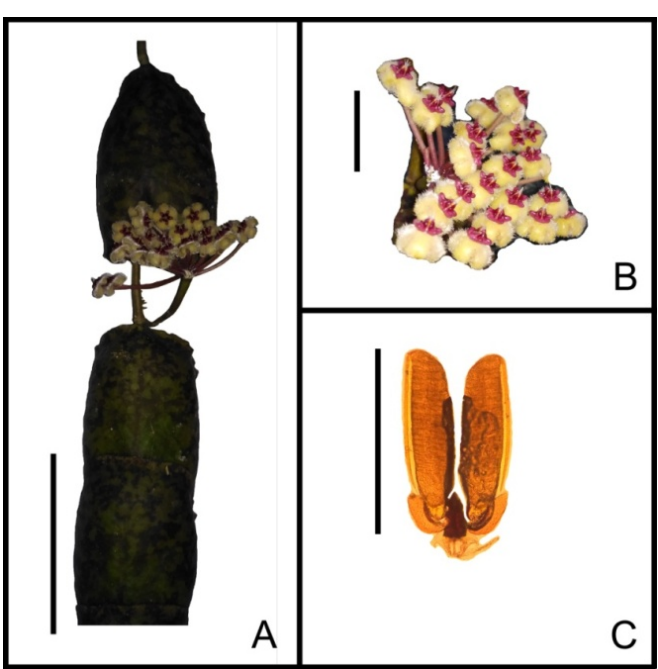

Gambar 3. A. H. imbricata, skala: $8 \mathrm{~cm}$. B. Inflorenscense, skala: 3 $\mathrm{cm}$. C. Pollinarium, skala: 0,5 $\mathrm{mm}$. Foto: Roland Putra Pribadi Ahmad, 2019

\section{PEMBAHASAN}

Gunung Sidole merupakan salah satu gunung yang secara administrasi terletak di Kecamatan Ampibabo, Kabupaten Parigi Moutong. Gunung Sidole memiliki ketinggian hingga $1900 \mathrm{~m}$ dpl dan setiap ketinggiannya memiliki vegetasi tumbuhan epifit yang beragam terdiri dari kelompok Orchidaceae, Apocynaceae, Gesneriaceae dan Pteridophyta. Hal tersebut sesuai Conchophyllum maximum $\mathrm{H}$. Karst., setelah pengamatan dua karakteristik bunga Dischidia, terapat perbedaan dari ukuran daun yang jauh berbeda (Karsten, 1895). Jenis ini awalnya dilaporkan berasal dari Sulawesi Utara (Karsten, 1895; Koorders, hanya dijumpai pada habitat agroforestry atau hutan perkebunan dengan ketinggian ca. $200 \mathrm{~m} \mathrm{dpl,} \mathrm{hal} \mathrm{ini} \mathrm{dikarenakan} \mathrm{karakter}$ dengan pendapat Sanford (1968) dan Johansson (1974), setiap ketinggian suatu wilayah memiliki perbedaan vegetasi tumbuhan epifit, karena komposisi jenis pohon dan atmosfer kelembaban sangat berbeda pada setiap ketinggian. Menurut Kleijn dan Donkelaar (2001), Hoya di Sulawesi dapat dijumpai hingga ketinggian $1200 \mathrm{~m}$ dpl, hal ini karena karakter struktur hutan pegunungan yang terbuka.

H. camphorifolia dapat terlihat tumbuh menjuntai pada pecabangan pepohonan. Jenis ini memiliki karakter yang dapat berubah ketika bertambahnya usia, seperti warna daun yang akan berubah dan ukuran batang yang berubah, sama seperti yang telah laporkan oleh Kleijn dan Donkelaar (2001) pada saat menjelajahi Sulaewesi, yaitu $H$. camphorifolia biasa ditemukan hingga ketinggian $600 \mathrm{~m} \mathrm{dpl}$, jenis ini biasanya menjuntai pada pohon besar, lingkungan yang tercemar akibat manusia atau antropogenik.

H. imbricata awalnya diketahui sebagai 1920). Menurut Kleijn dan Donkelaar (2001) $H$. imbricata sangat umum dijumpai pada ketinggian 0-600 m dpl di dataran Sulawesi Tengah.

Berdasarkan hasil penelitian, Hoya hutan perkebunan pada ketinggian $200 \mathrm{~m}$ dpl jauh lebih terbuka. Jenis yang 
didapatkan yaitu $H$. camphorifolia dan $H$. imbricata.

\section{Simpulan}

Dari penelitian yang telah dilakukan, terdapat 2 jenis Hoya dari Gunung Sidole yaitu: Hoya camphorifolia Warb. dan Hoya imbricata Decne.

\section{DAFTAR PUSTAKA}

Backer, C. A., dan van den Brink Jr, R. C. B. (1965). Flora of Java.Volume 2. Groningen: N.V.P. Noordhoff.

Johansson, D. (1974). Ecology of vascular epiphytes in West African rain forest. Acta Phytogeogr. Suec., 5, 1-136.

Karsten, G. (1895). Epiphytenformen der Molukken. Ann. Jard. Bot. Buitenzorg, 12, 154-168.

Kleijn, D., and van Donkelaar, R. (2001). Notes on the taxonomy and ecology of the genus Hoya (Asclepiadaceae) in Central Sulawesi. Blumea, 46, 457483.

Kloppenburg, D. (1993). Dr. Schlechter's Hoya species. USA: Library The New York Botanical Garden Bronx New York 10458. Hal 14-17.

Koorders, S. H. (1920). Untersuchungen über einege in den Jahren 1894-1895 von mir in N.O. Celebes gesammelten Pflanzen (mit 4 Tafeln). Supplement op het eerste overzicht der Flora van N.O. Celebes: $35-47$.

Lamb, A., and Rodda, M. (2016). A guide to Hoyas of Borneo. Kota Kinabalu: Natural History Publications Borneo.

Rahayu, S. (1997). Eksplorasi dan pembudidayaan Hoya (Asclepiadaceae). Dalam rangka konservasi plasma nutfah. Prosiding Seminar Nasional Konservasi Flora Nusantara (hal. 294-303). UPT BP Kebun Raya- LIPI Bogor.

Rintz, R. E. (1978). The peninsular Malaysian species of Hoya (Asclepiadaceae). Malayan Nature Journal,30, 467-522.

Rodda, M. (2015). Two new species of Hoya R.Br. (Apocynaceae, Asclepiadoideae) from Borneo. PhytoKeys, 53, 83-93.

Rugayah., Retnowati, A., Windadri, F.I., dan Hidayat, A. (2004). Pengumpulan data taksonomi. $\mathrm{Di}$ dalam Rugayah, Widjaja E.A., Praptiwi, (Ed.). Pedoman Pengumpulan Data Keanekaragaman Flora. Bogor (ID): Puslit-LIPI.

Schlechter, F. R. R. (1914). Die Asclepiadaceen von Deutsch-NeuGuinea. Engler's Bot. Jahreb, 50, 104138.

Simpson, M. G. (2006). Plant sytematics: Chapter 18 herbaria and data information system. USA: British Library Cataloguing in Publication Data.

Simonsson, N. J., dan Rodda, M. (2017). Contribution to a revision of Hoya (Apocynaceae: Asclepiadoidae) of Papuasia. Part I: Ten new species, one new subspecies and one new combination. Gardens' Bullettin Singapore,69(1), 97-147.

Rahayu, S. 2001. Keanekaragaman genetik Hoya asal Sumatra. [Thesis]. Program Pasca sarjana Institut Pertanian Bogor. Bogor.

Sanford, W. W. (1984). The distribution of epiphytic orchids in Nigeria in relation to each other and to geographic location and climate, type of 
Ahmad dan Ramadanil. Biocelebes. Desember. 2020. Vol. 14 No. 3, 229-236

vegetation and tree species. Biol. J. Linn. Soc. 1, 247-285.

Whitten, A. J., Mustafa, M., and Henderson,

G. S. (1987). The Ecology of

Sulawesi. Yogyakarta (ID): Gadjah

Mada University Press. 